\title{
REPRESENTAÇÕES SOCIAIS E SUSTENTABILIDADE: O SIGNIFICADO DO TERMO PARA ALUNOS DO CURSO DE ADMINISTRAÇÃO
}

\author{
SOCIAL REPRESENTATIONS AND SUSTAINABILITY: \\ THE MEANING OF THE TERM FOR \\ ADMINISTRATION STUDENTS
}

Recebido em: 17/09/2012 Aprovado em: 25/10/2012 Avaliado pelo sistema double blind review Editora Científica: Manolita Correia Lima

\section{FÁTIMA REGINA NEY MATOS fneymatos@unifor.br UNIVERSIDADE DE FORTALEZA}

\author{
ANA SILVIA ROCHA IPIRANGA \\ UNIVERSIDADE ESTADUAL DO CEARÁ \\ DIEGO DE QUEIROZ MACHADO \\ UNIVERSIDADE DE FORTALEZA \\ GERMANA FERREIRA ROLIM \\ UNIVERSIDADE FEDERAL DO CEARÁ

\section{RAFAELLA ALVES MEDEIROS ALVARENGA \\ UNIVERSIDADE DE FORTALEZA}

\begin{abstract}
RESUMO
Considerando as atuais discussões sobre sustentabilidade, desenvolvimento, desenvolvimento sustentável e tendo como base a abordagem da teoria das representações sociais, o objetivo desse estudo foi identificar os significados da palavra sustentabilidade para alunos do curso de administração de uma Instituição de Ensino Superior pública. O intuito consistiu em evidenciar as representações sociais que a ela subjazem ou dela decorrem, identificando seus significados com base na determinação do núcleo central e sistema periférico e relacionando-os às dimensões sociais, econômicas, ecológicas, espaciais e culturais. Para tanto, foi realizada uma pesquisa exploratória e descritiva, sendo o universo formado por 132 alunos matriculados no curso de administração de empresas de uma universidade pública de Fortaleza, utilizando-se o critério de acessibilidade. A técnica de coleta utilizada foi o teste de evocação de palavras e a palavra indutora foi sustentabilidade. Dessa forma, pôde-se constatar a permanência da representação da sustentabilidade, nucleada basicamente no meio ambiente. Este achado confirma o pressuposto inicial de que permanece o significado naturalista do conceito, de certa forma dissociado das demais dimensões do desenvolvimento sustentável.
\end{abstract}

Palavras-chave: desenvolvimento sustentável; representações sociais; teste de evocação de palavras.

\section{ABSTRACT}

Starting with the current discussions of sustainability, development and sustainable development, and employing asocial representations theory approach, the aim of this study was to identify the meanings the word sustainability has for business administration students at a Public Higher Education Institution. The goal was to highlight the social representations that underlie it or were created as a consequence of it, identifying its meanings based on the determination of the central core and peripheral system, as well as relating them to social, economic, ecological, cultural and spatial aspects. To this end, exploratory, descriptive research was undertaken with the sample formed by 132 business administration students from a public university in Fortaleza, with the criterion of accessibility employed. The collection technique used was a word evocation test and the inducing word was sustainability. It was possible to state the permanence of sustainability's representation, which was basically centered on environment. This finding confirms the initial assumption that a naturalist meaning remains for the concept, and there is a certain break with the other dimensions of sustainable development. Keywords: sustainable development; social representations; word evocation test. 


\section{INTRODUÇÃO}

Morin (1962, p. 33) ensina que "há palavras que se tornam demasiado pesadas, que acabam por se fazer esmagadas pelos seus conteúdos e que, à força de tudo terem explicado, exigem uma explicação". Pode-se considerar que as palavras "desenvolvimento" e "sustentabilidade" encontram-se nessa categoria, pois mesmo sendo conceitos interdisciplinares e, por assim serem, frequentemente relacionados e intensamente debatidos por diferentes campos disciplinares, ainda requerem explicações ao receber diferentes adjetivações e significações.

A perspectiva da sustentabilidade é aqui conceituada, conforme Sachs (200I), como a necessidade de criar novos modos de produção e estilos de vida, nas condições e potencialidades ecológicas de regiões e territórios específicos, na diversidade sociocultural e étnica e na gestão participativa dos recursos. Neste sentido, Leff (200I) aponta para a necessidade de desconstruir o paradigma do desenvolvimento com foco predominante no aspecto econômico, por meio da ideia do desenvolvimento sustentável, que deve ser fundamentado nos limites das leis da natureza, nos potenciais ecológicos, na produção de sentidos sociais e na criatividade humana. Desta forma o desenvolvimento sustentável é definido pela Comissão Brundtland, como aquele que "satisfaz às necessidades do presente, sem comprometer a capacidade das gerações futuras satisfazerem as suas próprias necessidades" (CMMAD, I99I, p. 46).

Nesse contexto de discussão, Sachs (1986) destaca que, para se tornarem eficazes, as estratégias de transição para o desenvolvimento sustentável ou o ecodesenvolvimento, devem se basear em cinco dimensões, quais sejam: sustentabilidade social, sustentabilidade econômica, sustentabilidade ecológica, sustentabilidade espacial e sustentabilidade cultural. Para este e outros autores, como Buarque (2006), estas dimensões apontam que o princípio da sustentabilidade é resultante da interação e sinergia entre a qualidade de vida da população local, a eficiência econômica e a gestão pública eficiente. 
Considerando estas discussões sobre sustentabilidade, desenvolvimento, desenvolvimento sustentável e tendo como base o aporte da teoria das representações sociais, o objetivo desse estudo foi identificar os significados da palavra sustentabilidade para alunos do curso de administração de uma Instituição de Ensino Superior pública, mostrando as representações sociais que a ela subjazem ou dela decorrem, identificando seus significados com base na determinação do núcleo central e sistema periférico e relacionandoos às dimensões sociais, econômicas, ecológicas, espaciais e culturais.

Vale ressaltar que, neste estudo, o conceito de representação social utilizado se fundamenta nas ideias de Moscovici (2003), sendo apresentada como um tipo de conhecimento do senso comum, formado por conceitos e imagens sobre pessoas, eventos, fenômenos do cotidiano, que são aceitos e considerados verdadeiros, mesmo sendo somente representações. Assim, uma representação social não é o puro reflexo das determinações objetivas, mas um sistema de interpretação de uma relação, ou de um tipo de realidade social que relaciona um conjunto de elementos de diferentes naturezas, sendo estes cognitivos, sociais, afetivos, valorativos e ideológicos (JODELET, I992; GUARESCHI; JOVCHELOVITCH, 1994).

Em complemento a essa abordagem das representações sociais, tomou-se como base as cinco dimensões do desenvolvimento sustentável, propostas por Sachs (1986) - sustentabilidade social, sustentabilidade econômica, sustentabilidade ecológica, sustentabilidade espacial e sustentabilidade cultural-, pois o núcleo de significados da representação social torna estáveis e permanentes os conceitos. Dessa forma, pressupõe-se que permanece o significado naturalista do conceito de sustentabilidade, dissociado das demais dimensões.

Em termos metodológicos, a pesquisa de caráter exploratório e descritivo baseia-se na abordagem de natureza qualitativa, segundo o escopo do levantamento. Como técnica de coleta e organização de dados, fez-se uso do teste de evocação de palavras junto aos I32 participantes dessa pesquisa, todos os alunos matriculados no curso de administração de empresas de uma universidade pública de Fortaleza. Deste modo, este estudo se 
apresenta como um esforço inédito da utilização de tais procedimentos metodológicos, fundamentados na abordagem das representações sociais, em investigações acerca da sustentabilidade e seus significados para futuros gestores.

Para tanto, este artigo está estruturado em seis partes, incluindo esta introdução. Primeiramente é apresentada uma breve contextualização sobre os conceitos de sustentabilidade, desenvolvimento e desenvolvimento sustentável, seguida de discussões sobre a teoria das representações sociais, com seu núcleo central e sistema periférico. Posteriormente, são descritos os procedimentos metodológicos utilizados, onde são apresentados o delineamento da pesquisa, o universo e os instrumentos de coleta e análise dos dados. A seguir, são discutidos os resultados obtidos; e, por fim, são tecidas as considerações finais. 


\section{DESENVOLVIMENTO, SUSTENTABILIDADE E O DESENVOLVIMENTO SUSTENTÁVEL}

A ciência econômica ou arte de enriquecer, de acordo com Aristóteles (I988), era de dois tipos: a economia doméstica e a crematística. A economia doméstica se interessava "mais pelos seres humanos da casa que por seus bens inanimados, e mais pelas qualidades daqueles que pelas de seus bens, que denominamos riquezas, e mais por seus membros livres que pelos escravos” (ARISTÓTELES, I988, p. 3I). Já a crematística tinha natureza comercial e estava ligada à usura, "cujo ganho vem do próprio dinheiro, e não daquilo que levou à sua invenção” (ibid., p. 28). Apesar de o pensamento aristotélico considerar a economia doméstica necessária e louvável e censurar a crematística, foi esta última que forneceu os fundamentos para o conceito da economia moderna para desenvolvimento.

Em sua base histórica, o desenvolvimento sempre esteve relacionado ao crescimento econômico, sendo resultante deste último. Braudel (I998) aponta que o termo desenvolvimento nasceu com a engrenagem das trocas, que favoreceu o surgimento das feiras e mercados, característicos do setor terciário, e o advento do estado/mercado nacional. Apesar de não ter sido produto da Revolução Industrial, foi a partir desta que a história da humanidade passou a ser quase inteiramente determinada pelo fenômeno do crescimento econômico relacionado ao desenvolvimento (vEIGA, 2006). Desde então, ganhou força uma visão quantitativa do mundo, sem considerar os processos qualitativos históricos, culturais e ambientais, ou seja, desconsiderando os aspectos sociais.

É importante enfatizar que essa desconsideração pelos aspectos sociais vem a manter as regras do capitalismo, quais sejam as relações de propriedade e de apropriação, o que corrobora para a reprodução de uma situação de desigualdade social, principalmente da pobreza. A pobreza é característica do subdesenvolvimento e, para Indira Gandhi, estadista indiana, que conviveu com a situação da governar um país de proporções continentais com 250 milhões de indigentes, a miséria é a pior forma de 
poluição (sACHs, 2004). Corroborando essa afirmação, o Relatório "Nosso Futuro Comum" aponta a pobreza como uma das principais causas dos problemas ambientais do planeta (CMAAD, I99I).

Como exemplo desta discussão, visualiza-se no período pós-guerra, até aproximadamente a década de 1970, a expansão econômica, com a indústria automobilística, siderúrgica, de borracha, de equipamentos elétricos, eletrônica de consumo, telefonia e petróleo fazendo uso de uma matriz energética de crescimento intensiva em energia-petróleo (PEREZ, 1985). Os recursos naturais foram considerados infinitos e, até 1973 , foi registrado um período de expansão denominado de petro-prosperidade (FURTADO, 2005). Sabe-se que tal expansão, após a Segunda Guerra, de acordo com Sunkel e Paz (1988), derivou da pretensão dos aliados de extinguir do mundo os problemas de desemprego, miséria, discriminação racial, desigualdades políticas, econômicas e sociais. Foi nesse período que nasceu a palavra subdesenvolvimento, ressaltada na definição de desenvolvimento de Outhwaite e Bottomore (1996, p. 197): "conquista do progresso econômico e social por meio da transformação do estado de subdesenvolvimento (baixa produção, estagnação, pobreza)", sendo o desenvolvimento relacionado ao crescimento econômico mais que ao progresso social.

Neste sentido, é corroborada a definição de Furtado (I96I, p. III), que considera que "do ponto de vista econômico, desenvolvimentoé, basicamente, aumento do fluxo de renda real, isto é, incremento da quantidade de bens e serviços, por unidade de tempo, à disposição de determinada coletividade”. Em complemento, Milone (1998) acrescenta que a variação positiva de crescimento econômico deve considerar os indicadores de renda, renda per capita, PIB e PIB per capita, redução dos níveis de pobreza, desemprego e desigualdade e melhoria dos níveis de saúde, nutrição, educação, moradia e transporte.

Na tentativa de esclarecer a diferença entre crescimento e desenvolvimento, Sachs (2006, p. 9) aponta que "desenvolvimento não se confunde com crescimento econômico, que constitui apenas a sua condição necessária, porém não suficiente". Assim, o crescimento econômico, apesar de condição necessária, não é suficiente para reduzir a pobreza e a desigualdade social, 
sendo fundamentais a qualidade e a estrutura do crescimento, pelos impactos que causam sobre o nível de emprego, meio ambiente, qualidade de vida e distribuição da renda (KLIKSBERG, 1997). Simplificando, Veiga (2006) indica que no crescimento ocorre uma mudança quantitativa, enquanto no desenvolvimento a mesma é qualitativa.

Na corrente contra-hegemônica do desenvolvimento como sinônimo de crescimento econômico, encontra-se o pensamento de Schumacher (1979, p. I49), para quem "o desenvolvimento não se inicia com bens materiais; começa com pessoas e sua educação, organização e disciplina. Na ausência desses três elementos, todos os recursos permanecem latentes, inexplorados, potenciais". Em concordância com o pensamento aristotélico, para este autor, o desenvolvimento necessariamente zelará pelas pessoas, que são a fonte primária e suprema de toda e qualquer riqueza.

Mais recentemente, Sen (2000) faz distinção entre duas atitudes gerais em relação ao processo de desenvolvimento: "uma visão considera o desenvolvimento um processo 'feroz', com muito 'sangue, suor e lágrimas' - um mundo no qual sabedoria requer riqueza. [...] a outra vê o desenvolvimento essencialmente como um processo 'amigável’” (p. 5I). Esta visão foi possível a partir do surgimento de um novo paradigma de desenvolvimento, que se originou, de acordo com Buarque (2006, p. 57) com "a publicação do primeiro Relatório do Clube de Roma, Os limites do crescimento (MEADOws et al., 198I), em 1969" (itálicos no original) e apoiado pela crise do petróleo, em 1973. Foi na Conferência das Nações Unidas de Desenvolvimento e Meio Ambiente (ECO-92), realizada no Rio de Janeiro, que foi proposto um modelo de desenvolvimento aliado à sustentabilidade, qual seja o do desenvolvimento sustentável.

Desenvolvimento sustentável, definido pela Comissão Brundtland, "é aquele que satisfaz às necessidades do presente, sem comprometer a capacidade das gerações futuras satisfazerem as suas próprias necessidades" (CMMAD, 1991, p. 46). Pode-se observar que o conceito de sustentabilidade nasceu de uma proposta de mudança forçada por condições ambientais. Nascia um novo paradigma de desenvolvimento, motivado pela certeza de que "a vitória do homem sobre a natureza, como se esmagar a natureza 
fosse a mais épica das façanhas, [...] conduziria ao suicídio; a natureza vencida é a destruição do homem" (MORIN, 1979, p. 80).

Este conceito, na visão de Foladori(2005), énecessariamenteinterdisciplinar e já nasceu incorporado à sustentabilidade ambiental, uma sustentabilidade econômica e social. A sustentabilidade é a expressão de uma sociedade mais justa e pressupõe o equilíbrio entre saúde, ambiente e desenvolvimento, dentro de um processo democrático, com ampla participação social e de exercício de cidadania (DUVAL, I998).

De acordo com Sachs (200I), a perspectiva da sustentabilidade impõe a necessidade de criar novos modos de produção e estilos de vida, nas condições e potencialidades ecológicas de regiões e territórios específicos, na diversidade sociocultural e étnica e na gestão participativa dos recursos. Em complemento, Badiru (20I0) ressalta a sua aplicação mediante um rigor metodológico, científico e analítico, a fim de torná-la eficaz no gerenciamento das atividades humanas e dos recursos. Nesse sentido, Sachs (1986) aponta que, para se tornarem eficazes, as estratégias de transição para o desenvolvimento sustentável ou ecodesenvolvimento devem obedecer a cinco dimensões:

- Sustentabilidade social - visando à distribuição de renda e de bens (oportunidades) com propósitos de reduzir o abismo entre ricos e pobres;

- Sustentabilidade econômica - a eficiência econômica avaliada em termos macrossociais, não em termos microeconômicos ou empresariais;

- Sustentabilidade ecológica - novas e criativas formas de intervenção do indivíduo humano na natureza, com níveis mínimos de abuso ou parasitismo;

- Sustentabilidade espacial - equilíbrio rural urbano, evitando a hiperurbanização;

- Sustentabilidade cultural - respeito e estímulo à diversidade, aos valores e saberes locais de cada população.

Estas dimensões apontam que o princípio da sustentabilidade é resultante da "interação e sinergia entre a qualidade de vida da população local redução da pobreza, geração de riqueza e distribuição de ativos -, a eficiência econômica - com agregação de valor na cadeia produtiva - e a gestão pública 
eficiente" (BUARQUE, 2006, p. 27 - itálicos no original). Seguindo esta linha de pensamento complexo, Bernal e Edgar (2012) propõem a incorporação de uma dimensão semelhante à sustentabilidade cultural de Sachs (200I), chamada pelos autores de dimensão da consciência profunda do ser humano, que ressalta o relacionamento dos indivíduos consigo e com a sociedade neste contexto.

É válido salientar que, apesar de estruturas e redes sociais não terem sido usualmente objeto de estudos econômicos, Polanyi (2000) apresentou, ainda em meados da década de 1940, a ideia de que a atividade econômica está imersa, inserida, embutida (embedded) na teia social e na cultura da sociedade. Granovetter (I992) corroborou a importância dos aspectos sociais sobre a atividade econômica, enfatizando a influência das relações sociais na vida econômica, mais até do que os dispositivos institucionais ou a existência de uma moral generalizada.

Em um período como o atual, no qual o capitalismo procura adequar suas estruturas de domínio para a manutenção da economia de mercado, é importante conhecer a representação social de futuros administradores sobre a sustentabilidade, tendo em vista que é na representação que se formam visões compartilhadas do grupo. Para tanto, Audebrand (2010), diante das dificuldades no ensino da sustentabilidade, ressalta o uso de metáforas no processo de educação em gestão sustentável, sendo tais metáforas nada mais do que a manifestação de representações deste fenômeno. O propósito desse processo estaria em aumentar o envolvimento desses administradores, em todos os níveis organizacionais (FIBUCH; VAN WAY III, 20I2), em iniciativas sustentáveis em suas organizações, ao contrário do observado em outros profissionais, como relatam Ballou, Casey, Grenier e Heitger (2012).

Ademais, o paradigma emergente da sustentabilidade pode ser indício do que vaticina Polanyi (2000, p. II): “o que nossa época precisa é a reafirmação, pelas suas próprias necessidades, dos valores essenciais da vida humana”, valores como confiança, cooperação, colaboração e comunhão, que permitam ao homem se organizar e construir o desenvolvimento sustentável. Dessa forma, para potencializar o ensino da sustentabilidade, 
principalmente no contexto ressaltado das escolas de gestão, novos caminhos e estratégias, como as propostas por Jacobi, Raufflet e Arruda (20II), relativas à criação de comunidades de aprendizado, que favoreçam uma aprendizagem social, integrando conhecimentos para além das fronteiras organizacionais, tornam-se cada vez mais necessárias. Dentro deste conjunto de possibilidades de exploração da temática sustentável no ambiente de aprendizagem dos futuros gestores, uma análise dos conceitos e representações já presentes nestes indivíduos acaba por adquirir nova importância. 


\section{REPRESENTAÇÕES SOCIAIS E O CONHECIMENTO DO COTIDIANO}

Durkheim (1978), em sua obra As formas elementares da vida religiosa, sustenta que a religião possibilitou o surgimento dos primeiros sistemas de representações que o homem fez do mundo e de si mesmo. As representações religiosas são representações coletivas, tendo em vista que exprimem realidades coletivas. Nesse sentido, a sociedade se sobrepõe ao indivíduo, sendo a mais alta manifestação da natureza e, assim sendo, as representações coletivas sempre acrescentam alguma coisa às representações individuais.

Contudo, de acordo com Herzlich (199I), a visão durkheimiana de priorizar a sociedade em detrimento do indivíduo é considerada reducionista, pois minimiza as possibilidades de manifestações individuais. De fato, Durkheim (1978) considerava a consciência coletiva como a forma mais elevada de vida psíquica. Diante desse posicionamento, Minayo (1995) e Cavedon (2003) situam as obras desse autor como o marco para a origem da abordagem das representações sociais.

Não obstante o termo representação tenha um longo passado, seja na filosofia, na psicologia, seja na sociologia, neste estudo ele se refere ao significado proposto por Serge Moscovici, considerado o maior representante da vertente europeia da teoria. Moscovici (1995) considera que a representação social funciona como uma forma de mediar o conflito entre o individual e o social, buscando um equilíbrio e uma complementaridade entre essas categorias. Em complemento, Jovchelovitch (1995, p. 78) aponta que "o sujeito não está subtraído da realidade social, nem meramente condenado a reproduzi-la. Sua tarefa é elaborar a permanente tensão entre um mundo que já se encontra constituído e seus próprios esforços para ser um sujeito".

Assim, a "representação social é uma forma de conhecimento específico ou saber do senso comum, cujos conteúdos se constroem a partir de processos socialmente marcados" (JODELET, 1992, p. I23). Constroem-se as representações sociais quando as pessoas se comunicam, conversam sobre suas práticas cotidianas, bem como quando estão expostas às instituições, 
aos meios de comunicação, aos mitos e à herança histórico-cultural de suas sociedades (GUARESCHI; JOVCHELOVITCH, 1994). De acordo com estes autores, a teoria das representações sociais "questiona ao invés de adaptar-se e [...] busca o novo, lá mesmo onde o peso hegemônico do tradicional impõe as suas contradições" (p.r7).

Neste cenário, o conhecimento do senso comum, relegado pela ciência moderna, vem sendo crescentemente resgatado. Souza Santos (1989) sugere uma reabilitação do que chama lumpendiscursos, e Alves (2005, p. I2) indica que "a aprendizagem da ciência é um processo de desenvolvimento progressivo do senso comum" (itálico no original). Assim, a utilidade da teoria das representações sociais se revela na busca de melhor compreensão das práticas coletivas. Por meio do conhecimento da representação social, é possível um entendimento mais adequado dos processos de constituição simbólica encontrados na sociedade e na qual os indivíduos se engajam, dando sentido ao mundo e nele construindo sua identidade social (GOMES; SÁ; OLIVEIRA, 2003; JOVCHELOVITCH, I995).

Sendo assim, principalmente nos últimos anos, tem-se produzido número considerável de pesquisas científicas, que se utilizam desta abordagem (por exemplo, KALISH; LAWSON, 2008; GORGORIÓ; ABREU, 2009; SOUZA-FILHO; BELDARRAIN-DURANDEGUI, 2009; FAGUNDES; ZANELLA; TORRES, 2OIO; POESCHL; RIBEIRO, 2OIO; SARRICA; WACHELKE, 2OIO; FLOWERS; SWAN, 2OII; SANTOS; ACIOLI NETO; SOUZA, 2OII; LESCURA; BRITO; BORGES; CAPPELLE, 2OI2; TORELLI et al., 20I2; VIZCARRA, 20I2), cuja contribuição reside em produzir reflexões e possibilitar o desenvolvimento das ciências nos seus mais diversos campos, como defendem Bovina e Dragul'skaia (2008). Além disso, segundo Parales-Quenza e Vizcaíno-Gutiérrez (2007) e Castorina e Barreiro (2010), o conhecimento das representações sociais presentes nos indivíduos é fundamental para o entendimento do seu próprio comportamento, já que tais representações seriam responsáveis por influenciar suas ações individuais. Como afirma Herner (2010, p. 152):

As representações sociais constituem sistemas cognitivos nos quais é possível reconhecer a presença de estereótipos, opiniões, crenças, valores e normas que costumam ter una orientação atitudinal positiva ou negativa. 
Constituem-se, por sua vez, como sistemas de códigos, valores, lógicas classificatórias, princípios interpretativos e orientadores das práticas, que definem a chamada consciência coletiva, que é regida com força normativa na medida em que institui os limites e as possibilidades da forma em que as mulheres e os homens atuam no mundo.

Assim sendo, observa-se que as representações sociais não são necessariamente consensuais. Pelo contrário, o sentido que se atribui a um dado objeto, além do próprio processo de atribuição, constitui construções psicossociais, as quais integram a história pessoal de cada indivíduo com o resultado de suas interações grupais. Objetivando auxiliar na identificação da parte mais relevante de uma representação social, dos valores e percepções que são compartilhados com mais clareza e coesão pelo grupo investigado, pode-se trabalhar com o chamado núcleo central da representação social.

Abric (I976, apud sá, 2002) aponta que a organização de uma representação social apresenta a característica específica de ser organizada em torno de um núcleo central, que é formado por um ou mais elementos que dão significado à representação. $\mathrm{O}$ autor entende que:

A organização de uma representação apresenta uma característica particular: não apenas os elementos da representação são hierarquizados, mas, além disso, toda representação é organizada em torno de um núcleo central, constituído de um ou de alguns elementos que dão à representação o seu significado (ABRIC apud sá, 2002, P.62).

Desse modo, o núcleo central é formado pelas significações fundamentais da representação, aquelas que lhe atribuem identidade. Passando o núcleo central por transformações, cria-se uma nova identidade. Os valores que representam o núcleo central de uma representação social são aqueles que, geralmente, o sujeito não tem consciência ou não explicita, mas que, todavia, direcionam a sua ação e definem as suas atitudes. Em outras palavras, representam o que é inegociável, a essência da representação social, formada pela memória coletiva do grupo e suas normas.

Portanto, o núcleo central possui uma função consensual que objetiva a homogeneidade do grupo e que se caracteriza por ser estável, coerente, resistente à mudança, além de ser independente do contexto social e material 
imediato, ou seja, não é significativamente influenciável pelos fatos mais recentes. Autores como Madeira (200I) e Sá (2002) consideram que o núcleo central é decisivo na inflexão que o sentido de um dado objeto assume para um grupo, em um dado contexto histórico e cultural.

Em volta do núcleo central, há o sistema periférico, que abriga as diferenças de percepção entre os indivíduos, de modo a suportar a heterogeneidade do grupo e acomodar as contradições trazidas pelo contexto mais imediato (MADEIRA, 200I; MAZZotTi, 200I). O sistema periférico é composto dos elementos que se posicionam em volta do núcleo central, não constituindo valores inegociáveis. Pelo contrário, nele estão acomodados os conceitos, percepções e valores que o indivíduo até admite rever, negociar. Madeira (200I) e Sá (2002) explicam que ele pode até ser visto como uma forma de defesa do núcleo central, possibilitando o intercâmbio com outros grupos e proporcionando a evolução da representação social, sem chegar a modificála.

Enfim, as representações sociais se inserem em um conceito plural e bastante complexo. Mas, mesmo existindo várias acepções - umas mais aproximadas, outras, nem tanto - é possível identificá-las como dinâmicas e explicativas; englobando aspectos culturais, cognitivos e valorativos; possuindo dimensão histórica e transformadora. Compreendem um material de estudo expressivo, uma vez que correspondem a situações reais de vida e revelam a visão de mundo de um determinado grupo social. O que tem permitido a utilização, em trabalhos de pesquisa social, da teoria das representações sociais é seu aspecto inovador, que permite a apreensão e reabilitação da ordem simbólica, que rompe com a dicotomia estabelecida entre exterior e interior, sujeito e objeto.

Representações sociais, de acordo com Moscovici (2003, p. I8I), são "um conjunto de conceitos, proposições e explicações originado na vida cotidiana no curso de comunicações interpessoais". Nesse sentido, as representações sociais podem ser consideradas como meio de recriar a realidade buscando torná-la senso comum. Já que as representações sociais são fenômenos que estão ligados ao modo particular de pensar, tendo o poder de materializar ideias, elas também podem ser ligadas à maneira específica de entender e 
comunicar aquilo que já se sabe. Portanto, ao compreender as representações sociais de determinados atores, pode-se tentar apreender tanto a essência da realidade social, como a personalidade individual que interpreta, manipula e reage às regras e aos valores sociais. Ou seja, estudam-se as representações sociais como um modo de saber como um grupo humano constrói um conjunto de saberes, que expressam sua identidade social.

É nesse sentido que Jodelet (200I) esclarece que as representações são frutos da interação entre indivíduos integrados que, ao mesmo tempo, constroem e produzem uma história individual e também produzem uma história social. Conhecendo-se as representações sociais que são construídas, compreende-se o comportamento assumido por esse grupo e como estas atuam na motivação desses indivíduos. 


\section{PROCEDIMENTOS METODOLÓGICOS}

Em termos metodológicos, a pesquisa de caráter exploratório baseia-se na abordagem de natureza qualitativa, segundo o escopo do levantamento, pois o tema estudado ainda é passível de conhecimento sistematizado (VERGARA, 1997). É importante salientar que não se buscam respostas tidas como verdades, pois representações sociais estão em constante reformulação (FREITAS; CASTRO, 2004). O resultado que se procura é a compreensão e descrição do significado de um termo, o que torna a pesquisa também descritiva em termos de delineamento.

Tendo como objetivo identificar os significados da palavra sustentabilidade para alunos do curso de administração de uma Instituição de Ensino Superior pública, seu universo de pesquisa foi formado por 132 alunos matriculados no curso de administração de empresas de uma Instituição de Ensino Superior pública de Fortaleza, utilizando-se o critério de acessibilidade.

Estando este estudo baseado nos aportes da teoria das representações sociais, utilizou-se o teste de evocação de palavras (TEVOC) como técnica de coleta de dados (vergara, 2008). Esta técnica foi aplicada visando levantar elementos que, possivelmente, compõem a estrutura da representação do objeto em estudo. A palavra indutora foi "sustentabilidade".

Neste procedimento, foi solicitado aos alunos que mencionassem por escrito as quatro primeiras palavras ou expressões, que viessem espontaneamente à mente, baseadas no termo indutor "sustentabilidade". Considerou-se a ordem de citação espontânea das palavras ou expressões como a ordem de importância atribuída pelos entrevistados.

Os dados foram tratados e categorizados tendo como base medidas de estatística descritiva, considerando-se a conjugação da frequência/ média e da ordem de evocação das palavras, o que implica contemplar, respectivamente, a dimensão coletiva e a individual. Fez-se uso dos softwares Excel e spss, versão 15, para facilitar o processo de organização e análise dos dados coletados. 


\section{DISCUSSÃO DOS RESULTADOS}

\section{DETALHAMENTO DO TESTE DE EVOCAÇÃO DE PALAVRAS}

Foram entrevistados I32 alunos de uma universidade pública na cidade de Fortaleza. Foi solicitado que os alunos mencionassem as quatro primeiras palavras baseadas no termo indutor "sustentabilidade". Ao todo foram coletadas e listadas 5I2 respostas, classificadas em 208 categorias.

Das 208 categorias, foram selecionadas para o cálculo do teste de evocação as 20 primeiras categorias de maior frequência simples. Foram desprezadas as demais, pois alcançaram, isoladamente, menos que 0,7\% da frequência simples, sendo esse o critério para determinar as categorias pouco significativas. A Tabela I apresenta as categorias, frequências e ordens médias de evocação.

Tabela 1 Categorias, frequências e ordens médias de evocação

\begin{tabular}{|c|c|c|c|c|c|c|}
\hline Categorias & $\begin{array}{l}\text { Freq. } \\
\text { 10 lugar }\end{array}$ & $\begin{array}{l}\text { Freq. } \\
2 \circ \text { lugar }\end{array}$ & $\begin{array}{l}\text { Freq. } \\
3^{\circ} \text { lugar }\end{array}$ & $\begin{array}{l}\text { Freq. } \\
4^{\circ} \text { lugar }\end{array}$ & $\begin{array}{l}\Sigma \text { das freq. } \\
\text { de evocação }\end{array}$ & $\begin{array}{l}\text { Ordem média de } \\
\text { evocação }\end{array}$ \\
\hline Meio ambiente & 12 & 12 & 1 & 5 & 30 & 1,97 \\
\hline Necessidade & 9 & 3 & 6 & 4 & 22 & 2,23 \\
\hline Responsabilidade & 6 & 5 & 5 & 3 & 19 & 2,26 \\
\hline Consciência & 6 & 2 & 6 & 0 & 14 & 2,00 \\
\hline Futuro & 4 & 1 & 7 & 2 & 14 & 2,50 \\
\hline Importante & 3 & 3 & 5 & 3 & 14 & 2,57 \\
\hline Inovação & 6 & 2 & 3 & 1 & 12 & 1,92 \\
\hline Desenvolvimento & 0 & 4 & 4 & 1 & 9 & 2,67 \\
\hline Organização & 2 & 1 & 1 & 5 & 9 & 3,00 \\
\hline Respeito & 0 & 4 & 4 & 1 & 9 & 2,67 \\
\hline Ética & 1 & 2 & 2 & 2 & 7 & 2,71 \\
\hline Marketing & 2 & 0 & 5 & 0 & 7 & 2,43 \\
\hline Lucro & 5 & 1 & 0 & 0 & 6 & 1,17 \\
\hline Planejamento & 0 & 2 & 1 & 3 & 6 & 3,17 \\
\hline Compromisso & 1 & 0 & 3 & 1 & 5 & 2,80 \\
\hline Crescimento & 0 & 1 & 0 & 4 & 5 & 3,60 \\
\hline Essencial & 5 & 0 & 0 & 0 & 5 & 1,00 \\
\hline
\end{tabular}




\begin{tabular}{lllllll} 
Categorias & $\begin{array}{l}\text { Freq. } \\
1^{\circ} \text { lugar }\end{array}$ & $\begin{array}{l}\text { Freq. } \\
\mathbf{2}^{\circ} \text { lugar }\end{array}$ & $\begin{array}{l}\text { Freq. } \\
3^{\circ} \text { lugar }\end{array}$ & $\begin{array}{l}\text { Freq. } \\
4^{\circ} \text { lugar }\end{array}$ & $\begin{array}{l}\boldsymbol{\Sigma} \text { das freq. } \\
\text { de evocação }\end{array}$ & $\begin{array}{l}\text { Ordem média de } \\
\text { evocação }\end{array}$ \\
\hline Objetivo & 0 & 1 & 1 & 3 & 5 & 3,40 \\
Preservação & 1 & 1 & 1 & 2 & 5 & 2,80 \\
Progresso & 1 & 3 & 0 & 1 & 5 & 2,20 \\
Total & & & & & 208 & 49,1 \\
\hline
\end{tabular}

Efetuados os cálculos de frequência e da ordem média de evocação de cada uma das 20 categorias significativas, pode-se chegar aos resultados da frequência média de evocação em Io,40 e, para a média aritmética das ordens médias de evocação, ao valor de 2,45. Sendo assim, os critérios de distribuição no diagrama de quatro quadrantes são apresentados na Tabela 2 .

Tabela 2 Critérios de distribuição do diagrama

\begin{tabular}{l|l|l|}
\hline $\begin{array}{l}\text { Frequência média } \\
\text { de evocação }\end{array}$ & $\begin{array}{l}\text { Eixo vertical } \\
\text { (valores } \geq 10,40 \text { devem ser alocados na parte superior) }\end{array}$ \\
$\begin{array}{l}\text { Média das ordens médias } \\
\text { de evocação }\end{array}$ & 2,45 & $\begin{array}{l}\text { Eixo horizontal } \\
\text { (valores } \leq 2,45 \text { devem ser alocados do lado esquerdo) }\end{array}$
\end{tabular}

A frequência média de evocação determina que as palavras, cujo somatório das frequências de evocação tiver um valor superior ou igual a ıo,40, estarão em um dos quadrantes superiores. Já a média das ordens médias de evocação determina que as palavras com ordem média de evocação com valores iguais ou inferiores a 2,45 estarão em um dos quadrantes esquerdo. Assim, a determinação de qual quadrante a palavras estará é a combinação dos dois resultados. 


\section{O CONCEITO DE SUSTENTABILIDADE E SUAS REPRESENTAÇÕES SOCIAIS}

No quadrante superior esquerdo posiciona-se o núcleo central, no qual se encontram as categorias com maior frequência e mais prontamente citadas. $\mathrm{O}$ quadrante inferior direito representa as categorias citadas com menor frequência e mais tardiamente. Os outros dois quadrantes, superior direito e inferior esquerdo, mantêm uma relação estreita com o núcleo central e formam o sistema periférico. Na Figura I, pode-se observar o diagrama formado:

Figura 1 Diagrama de Evocação

\begin{tabular}{|c|c|c|}
\hline \multirow{3}{*}{$\begin{array}{l}\text { Ordem média de } \\
\text { evocação }\end{array}$} & \multicolumn{2}{|l|}{ Frequência de Evocação } \\
\hline & $\begin{array}{l}\text { Meio ambiente, Necessidade, } \\
\text { Responsabilidade, Consciência, } \\
\text { Inovação }\end{array}$ & Futuro, Importante \\
\hline & Marketing, Lucro, Essencial, Progresso & $\begin{array}{l}\text { Desenvolvimento, Organização, } \\
\text { Respeito, Ética, Planejamento, } \\
\text { Compromisso, Crescimento, Objetivo, } \\
\text { Preservação }\end{array}$ \\
\hline
\end{tabular}

Com base nos resultados do teste de evocação de palavras, pode-se observar que os sujeitos constroem representações sociais sobre a palavra "sustentabilidade" em torno dos seguintes significados: meio ambiente, necessidade, responsabilidade, consciência e inovação. Estas palavras compõem o núcleo central da representação. Ressalta-se que a expressão "meio ambiente" apresentou o somatório mais elevado das frequências de evocação, aparecendo tanto no primeiro como no segundo lugar na ordem de evocação. O significado, bem como a construção do conceito de sustentabilidade, está então alicerçado na dimensão "sustentabilidade ecológica", proposta por Sachs (1986).

Necessidade, responsabilidade e consciência são os substantivos abstratos evocados pelo grupo pesquisado, que denotam uma condição inerente à existência da sustentabilidade. Na percepção dos respondentes é imprescindível que haja na sociedade a qualidade de ser necessário, de ser 
responsável e de ser consciente para que seja construído o significado do desenvolvimento sustentável.

Ainda compondo o núcleo central da representação, encontra-se a palavra inovação. O significado desta palavra vem ao encontro do novo paradigma de desenvolvimento, denotando a necessidade de criar novos modos de produção e estilos de vida, conforme proposto por Sachs (200I).

Como apresentado anteriormente, de acordo com Sá (2002), os elementos periféricos caracterizam, apoiam e protegem o núcleo central e abrigam as diferenças de percepção entre os indivíduos, de modo a suportar a heterogeneidade do grupo e acomodar as contradições trazidas pelo contexto mais imediato (MADEIRA, 200I, MAzzotTI, 200I). Pode-se observar esta heterogeneidade no quadrante inferior esquerdo, onde se concentram as palavras marketing, lucro essencial e progresso, inseridas no paradigma vigente de crescimento econômico. Também compondo o sistema periférico estão as palavras futuro e importante, que confirmam o núcleo central no sentido do paradigma emergente do ecodesenvolvimento.

Encontram-se no quadrante inferior direito as palavras citadas menos vezes e mais tardiamente: desenvolvimento, organização, respeito, ética, planejamento, compromisso, crescimento, objetivo, preservação. É importante salientar que as palavras "desenvolvimento" e "crescimento" aparecem no mesmo quadrante, ou seja, são pouco significativas na representação social da palavra "sustentabilidade", o que reforça o argumento de que meio ambiente tem pouca relação com o avanço econômico. A palavra "preservação", que o conhecimento do senso comum relaciona com "meio ambiente", foi pouco e tardiamente evocada.

Pode se observar, conforme consta no Quadro I, que segue, a relação das palavras evocadas com as dimensões propostas por Sachs (1986): 
Quadro 1 Dimensões do Ecodesenvolvimento e Representações Sociais de Sustentabilidade

\begin{tabular}{|c|c|}
\hline $\begin{array}{l}\text { Sustentabilidade social: visando à distribuição } \\
\text { de renda e de bens (oportunidades) com } \\
\text { propósitos de reduzir o abismo entre ricos e } \\
\text { pobres. }\end{array}$ & Organização, Inovação, Objetivo \\
\hline $\begin{array}{l}\text { Sustentabilidade econômica: a eficiência } \\
\text { econômica avaliada em termos macrossociais, } \\
\text { não em termos microeconômicos ou } \\
\text { empresariais. }\end{array}$ & $\begin{array}{l}\text { Marketing, Lucro Progresso, Crescimento, } \\
\text { Desenvolvimento, Futuro }\end{array}$ \\
\hline $\begin{array}{l}\text { Sustentabilidade ecológica: novas e criativas } \\
\text { formas de intervenção do indivíduo humano } \\
\text { na natureza, com níveis mínimos de abuso ou } \\
\text { parasitismo. }\end{array}$ & Meio ambiente, Preservação \\
\hline $\begin{array}{l}\text { Sustentabilidade espacial: equilíbrio rural } \\
\text { urbano, evitando a hiperurbanização. }\end{array}$ & Planejamento \\
\hline $\begin{array}{l}\text { Sustentabilidade cultural: respeito e estímulo à } \\
\text { diversidade, aos valores e saberes locais de cada } \\
\text { população. }\end{array}$ & $\begin{array}{l}\text { Ética, Respeito, Essencial, Compromisso, } \\
\text { Responsabilidade, Consciência, Importante }\end{array}$ \\
\hline
\end{tabular}

Os significados das palavras "organização", "inovação" e "objetivo" foram relacionados à dimensão da sustentabilidade social, pois são palavras de estímulo ao aumento de riquezas nas empresas ou pessoais. Já as palavras "ética", "respeito", "essencial”, "compromisso", "responsabilidade”, "consciência" e "importante" foram relacionadas à dimensão da sustentabilidade cultural, pois são substantivos e adjetivos que expressam valores.

Como o núcleo central tem a função de criar ou transformar significados, pode-se argumentar que está sendo criada uma representação social, prioritariamente, na perspectiva ecológica, mantendo-se o significado naturalista do conceito de sustentabilidade, de certa forma dissociada das demais dimensões do ecodesenvolvimento. 


\section{CONSIDERAÇÕES FINAIS}

Este estudo teve como objetivo identificar os significados da palavra sustentabilidade para alunos do curso de administração de uma Instituição de Ensino Superior pública, mostrando as representações sociais que a ela subjazem ou dela decorrem. Tal análise teve em vista identificar o estágio atual de desenvolvimento deste conceito na mente desses futuros gestores, tendo em vista que o conceito de sustentabilidade nasceu de uma proposta eminentemente ambiental, embora já tenha incorporado aspectos sociais, econômicos, organizacionais.

Caracterizando-se como uma pesquisa exploratória e de cunho descritivo, não se tratou, portanto, de um estudo com amostra ampla e suficientemente estratificada, que permitisse a extrapolação dos resultados alcançados para a população, em geral, ou mesmo para parte determinada dela. Deste modo, os resultados apresentados demonstram tão somente a percepção de alunos do curso de graduação em administração de empresas de uma Instituição de Ensino Superior pública de Fortaleza. Feita essa ressalva, pode-se elaborar algumas considerações finais.

Considerando que, conforme Morin (1979), uma representação social não é um reflexo de determinações objetivas, mas um sistema de interpretação de uma relação, os resultados dessa pesquisa evidenciaram a proposta contida no conceito de sustentabilidade quando afirma que este se originou da mudança paradigmática sobre a ideia de desenvolvimento como a vitória do homem sobre a natureza. Estas evidências se coadunam com as discussões tecidas no referencial teórico desse estudo, ao relevar que o conceito de sustentabilidade é interdisciplinar, envolvendo cinco dimensões: social, econômica, ecológica, espacial e cultural.

Moscovici (2003, p. 62) salienta que o modo como as representações são "construídas e adquiridas" é semelhante ao modo como se constroem e adquirem os conceitos teóricos. Assim, pode-se concluir que o conceito de sustentabilidade está sendo consolidado na perspectiva ecológica, pois o núcleo central, que tem a função de criar ou transformar significados, mostra que no desenvolvimento da representação social está se mantendo 
o significado naturalista do conceito, de alguma forma dissociado das demais dimensões do ecodesenvolvimento. No entanto, salienta-se que estudos com base na teoria das representações sociais apresentam um design flexível e deixam margem para continuidade, ora para confirmar, ora para questionar resultados, pois, como propõe Moscovici (2003), são estudos provisórios e abertos. Sendo assim, faz-se necessário o desenvolvimento de novos estudos que visem avaliar os achados encontrados neste estudo, seja pela exploração de diferentes universos, seja pela utilização de métodos distintos de pesquisa, a fim de validar, complementar ou ponderar seus achados.

Por fim, é importante salientar que a aplicação da teoria das representações sociais no campo disciplinar da administração pode contribuir para a construção do link entre teoria e prática, tendo em vista que o conhecimento obtido por meio destas representações sociais pode ajudar a compreender, produzir, reproduzir e interpretar os objetos e fenômenos do cotidiano, relacionando-os aos conceitos teóricos. Neste sentido, ressalta o caráter inovador desta pesquisa, ao contribuir para as investigações e debates acerca da baseada no reconhecimento de sua interdisciplinaridade e mediante abordagem da psicossociologia, adotante, entre seus objetos de pesquisa, das representações sociais. Dessa forma, este estudo contribui para a consolidação das investigações relativas à sustentabilidade, por meio da aplicabilidade de tais procedimentos metodológicos junto a um universo formado por futuros gestores de negócios. Além disso, destaca-se a perspectiva de sua transitoriedade pelas fronteiras entre as tradicionais disciplinas do conhecimento, constituindo-se como uma das inovadoras iniciativas de construção do diálogo entre a psicossociologia e a ecologia política. 


\section{REFERENNCIAS}

ALVES, R. Filosofia da Ciência - Introdução ao Jogo e suas Regras. 10.ed. São Paulo: Loyola, 2005.

ARISTÓTELES. Política. 2. ed. Brasília, DF: Editora Universidade de Brasília, 1988.

AUDEBRAND, L. K. Sustainability in Strategic Management Education: The Quest for New Root Metaphors. Academy of Management Learning \& Education, v. 9, n. 3, p. 413-428, 2010.

BADIRU, A. B. The many languages of sustainability. Industrial Engineer, v. 42, n. 11, p. 31-34, 2010.

BALLOU, B.; CASEY, R. J.; GRENIER, J. H.; HEITGER, D. L. Exploring the Strategic Integration of Sustainability Initiatives: Opportunities for Accounting Research. Accounting Horizons, v. 26, n. 2, p. 265-288, 2012.

BERNAL, E.; EDGAR, D. The Development of a Model of Sustainability Management, based on Biological Ethics. International Journal of Management, v. 29, n. 3, p. 177-188, 2012 .

BOVINA, I. B.; DRAGUL'SKAIA, L. I. College Students' Representations of Science and the Scientist. Russian Education and Society, v. 50, n. 1, p. 44-64, 2008.

BRAUDEL, F. Civilização Material, Economia e Capitalismo Séculos XV-XVIII - Os Jogos das Trocas. São Paulo: Martins Fontes, 1998. (volume 2).

BUARQUE, S. C. Construindo o Desenvolvimento Local Sustentável. Rio de Janeiro: Garamond, 2006.

CASTORINA, J. A.; BARREIRO, A. V. El proceso de individuación de las representaciones sociales: historia y reformulación de un problema. Interdisciplinaria, $\mathrm{v}$. 27, n. 1, p. 63-75, 2010.

CAVEDON, N. R. Antropologia para administradores. Porto Alegre: Ed. UFRGS, 2003.

CMMAD - Comissão Mundial sobre Meio Ambiente e Desenvolvimento. Nosso futuro comum. 2.ed. Rio de Janeiro: Editora da Fundação Getúlio Vargas, 1991. (Relatório Brundtland).

DURKHEIM, É. As formas elementares da vida religiosa. São Paulo: Abril Cultural, 1978. (Coleção Os Pensadores).

DUVAL, G. Salud y Ambiente en el proceso de desarrolo. Ciência \& Saúde Coletiva, v. 3, n. 2, p. 7-32, 1998.

FAGUNDES, M. M.; ZANELLA, M.; TORRES, T. L. Cidadão em foco: representações sociais, atitudes e comportamentos de cidadania. Psicologia: teoria e prática, v. 14, n. 1, p. 55-69, 2012.

FIBUCH, E.; VAN WAY III, C. W. Sustainability: A Fiduciary Responsibility of Senior Leaders? Physician Executive, v. 36-43, p. 36, 2012. 
FLOWERS, R.; SWAN, E. 'Eating at us': Representations of knowledge in the activist documentary film Food, Inc. Studies in the Education of Adults, v. 43, n. 2, p. 234-250, 2011. FOLADORI, G. Por una sustentabilidad alternativa. Casa Bertold Brecht UITA, 2005.

FREITAS, S. N.; CASTRO, S. F. Representação Social e Educação Especial: A Representação dos Professores de Alunos com Necessidades Educativas Especiais Incluídos na Classe Comum do Ensino Regular, 2004.

FURTADO, A. Opções tecnológicas e desenvolvimento do Terceiro Mundo. In: CASTRO, A. C.; LICHA, A.; PINTO JR., H.Q.; SABOIA, J. Brasil em desenvolvimento 1 Economia, tecnologia e competitividade. Rio de Janeiro: Civilização Brasileira, 2005.

FURTADO, C. Desenvolvimento e subdesenvolvimento. Rio de Janeiro: Fundo de Cultura, 1961.

GOMES, M. N. da L. M.; SÁ, C. P. de; OLIVEIRA, D. C.de. Representações sociais do ato infracional por adolescentes em conflito com a lei: uma comparação estrutural. In: JORNADA INTERNACIONAL 3 e CONFERENCIA BRASILEIRA SOBRE REPRESENTAÇÕES SOCIAIS, 1., Rio de Janeiro. Anais... Rio de Janeiro, [s.n.], 2003.

GORGORIÓ, N.; ABREU, G. Social representations as mediators of practice in mathematics classrooms with immigrant students. Educ. Stud. Math., v. 72, p. 61-76, 2009.

GRANOVETTER, M. Economic Action and Social Structure: The Problem of Embeddedness. In: GRANOVETTER, M.; SWEDBERG, R. The Sociology of Economic Life. San Francisco: Westview Press, 1992.

GUARESHI, P.; JOVCHELOVITCH, S. (Orgs.). Textos em Representações Sociais. 4.ed. Petrópolis: Vozes, 1994.

HERNER, M. T. La teoría de las representaciones sociales: un acercamiento desde la geografia. Huellas, n. 14, P. 150-162, 2010.

HERZLICH, C. A Problemática da Representação Social e sua Utilidade no Campo da Doença. Revista de Saúde Coletiva, v. 1, n. 2, Rio de Janeiro, IMS/UERJ/Relumé Dumará, 1991.

JACOBI, P. R.; RAUFFLET, E.; ARRUDA, M. P. Educação para a sustentabilidade nos cursos de administração: reflexão sobre paradigmas e práticas. RAM, v. 12, n. 3, p. 21-50, 2011.

JODELET, D. (Org.). As representações sociais. Rio de Janeiro: Uerj, 2001.

Folie et Représentations Sociales. In: ARRUDA, A. Representações sociais: emergência e conflito na psicologia social. São Paulo: Brasiliense, 1992.

JOVCHELOVITCH, S. Vivendo a vida com os outros: intersubjetividade, espaço público e representações sociais. In: GUARESCHI, P. A.; JOVCHELOVITCH, S. Textos em representações sociais. 2.ed. Petrópolis: Vozes, 1995. 
KALISH, C. W.; LAWSON, C. A. Development of Social Category Representations: Early Appreciation of Roles and Deontic Relations. Child Development, v. 79, n. 3, p. $577-$ 593, 2008.

KLIKSBERG, B. Falácias e Mitos do Desenvolvimento Social. São Paulo: Cortez, 2001. . Repensando el Estado para el desarrollo social: más allá de convencionalismos. Caracas, Revista del CLAD Reforma y Democracia, jan. 1997.

LEFF, E. Saber Ambiental. Petrópolis: Vozes, 2001.

LESCURA, C.; BRITO, M. J.; BORGES, A. F.; CAPPELLE, M. C. A. Representações Sociais sobre as Relações de Parentesco: Estudo de Caso em um Grupo Empresarial Familiar. RAC, v. 16, n. 1, p. 98-117, 2012.

MADEIRA, M. Representações sociais e educação: importância teórico-metodológica de uma relação. In: MOREIRA, A. P. (Org.). Representações sociais: teoria e prática. João Pessoa: UFPB, 2001.

MAZZOTTI, T. B. Representações sociais de problemas ambientais: uma contribuição à educação brasileira. In: MOREIRA, A. P. (Org.). Representações sociais: teoria e prática. João Pessoa: UFPB, 2001.

MILONE, P. C. Crescimento e desenvolvimento econômico: teorias e evidências empíricas. In: MONTORO FILHO, A. F. et al. Manual de economia. São Paulo: Saraiva, 1998.

MINAYO, M. C. S. O desafio do conhecimento: pesquisa qualitativa em saúde. São PauloRio de Janeiro: Hucitec-Abrasco, 1995.

MORIN, E. Ano 1 da era ecológica. In: MANSHOLT, S.; BOSQUET, M.; MORIN, E.; MARCUSE, H. e outros. Ecologia - Caso de vida ou de morte. 2.ed. Lisboa: Moraes Editores, 1979.

1962.

. O que não é burocracia. In: MORIN,E. et al. A Burocracia. Lisboa: Socicultur,

MOSCOVICI, S. Representações sociais. Investigações em psicologia social. Petrópolis: Vozes, 2003.

Prefácio. In: GUARESHI, P.; JOVCHELOVITCH, S. (Orgs.). Textos em representações sociais. 2. ed. Petrópolis: Vozes, 1995.

OLIVEIRA, G. B. de. Uma discussão sobre o conceito de desenvolvimento. In: OLIVEIRA, G. B. de; SOUZA-LIMA, J. E. de. (Orgs.). O Desenvolvimento Sustentável em Foco - Uma contribuição multidisciplinar. Curitiba: São Paulo: Annablume, 2006.

OUTHWAITE, W.; BOTTOMORE, T. Dicionário do Pensamento Social do Século XX. Rio de Janeiro: Zahar, 1996.

PARALES-QUENZA, C. J.; VIZCAÍNO-GUTIÉRREZ, M. Las relaciones entre actitudes y representaciones sociales: elementos para una integración conceptual. Revista Latinoamericana de Psicología, v. 39, n. 2, p. 351-361, 2007. 
PEREZ, C. Microeletronics, Long Waves and the World Structural Change: new perspectives for developing countries. World Development, v. 13, n. 3, p. 441-463, 1985. POESCHL, G.; RIBEIRO, R. Ancoragens e variações nas representações sociais da corrupção. Análise Social, v. 45, p. 419-445, 2010.

POLANYI, K. A Grande Transformação - As origens da nossa época. 8. ed. Rio de Janeiro: Campus, 2000.

SÁ, C. P. Núcleo central das representações sociais. 2.ed. Petrópolis: Vozes, 2002.

SACHS, I. Prefácio. In: VEIGA, J. E. Desenvolvimento sustentável - o desafio do século XXI. Rio de Janeiro: Garamond, 2006.

. Experiências Internacionais de um Cientista Inquieto. Entrevista com Ignacy Sachs. Estudos Avançados, v. 18, n. 52, São Paulo, dec. 2004. Vozes, 2001.

Ecodesarrollo: desarrollo sin destrucción. In: LEFF, E. Saber Ambiental. Petrópolis: . Ecodesenvolvimento: crescer sem destruir. São Paulo: Vértice, 1986.

SANTOS, M. F. S.; ACIOLI NETO, M. L.; SOUZA, Y. S. O. Adolescência em revistas: um estudo sobre representações sociais. Psicologia: teoria e prática, v. 13, n. 2, p. 103-113, 2011.

SARRICA, M.; WACHELKE, J. Paz y guerra como representaciones sociales: una exploración con adolescentes italianos. Universitas Psychologica, v. 9, n. 2, p. 315-330, 2010.

SCHUMACHER, E. F. O negócio é ser pequeno. 2. ed. Rio de Janeiro: Zahar Editores, 1979. SEN, A. Desenvolvimento como liberdade. São Paulo: Companhia das Letras, 2000.

SOUZA-FILHO, E. A.; BELDARRAIN-DURANDEGUI, A. The Contextual Analysis in Social Representations of the Body Among Ethnic Groups in Rio de Janeiro, Brasil. Universitas Psychologica, v. 8, n. 3, p. 771-783, 2009.

SOUZA SANTOS, B. de. Introdução a uma ciência pós-moderna. 4. ed. Rio de Janeiro: Graal, 1989.

SUNKEL, O.; PAZ, P. El sudesarrollo latinoamericano y la teoría del desarrollo. 22.ed. México: Siglo XX Editores, 1988.

TORELLI, C. J.; ÖZSOMER, A.; CARVALHO, S. W.; KEH, H. T.; MAEHLE, N. Brand Concepts as Representations of Human Values: Do Cultural Congruity and Compatibility Between Values Matter? Journal of Marketing, v. 76, p. 92-108, 2012.

VEIGA, J. E. Desenvolvimento sustentável - o desafio do século XXI. Rio de Janeiro: Garamond, 2006.

VERGARA, S. C. Métodos de Pesquisa em Administração, 3.ed. São Paulo: Atlas, 2008. Projetos e Relatórios de Pesquisa em Administração. São Paulo: Atlas, 1997.

VIZCARRA, F. Representaciones de la modernidad en el cine futurista. Nueva época, n. 17, p. 73-97, 2012. 


\section{DADOS DOS AUTORES}

FÁTIMA REGINA NEY MATOS ${ }^{\star}$ fneymatos@unifor.br

Doutora em Administração de Empresas pela UFPE

Instituição de vinculação: Universidade de Fortaleza

Fortaleza/CE - Brasil

Áreas de interesse em pesquisa: Arranjos produtivos, Desenvolvimento local e

Desenvolvimento sustentável.

* UNIFOR - PPGA (Sala Q - 3)

Avenida Washington Soares, n. 132L Edson Queiroz Fortaleza/CE 60811-341

ANA SILVIA ROCHA IPIRANGA ana.silvia@pq.cnpq.br

Doutora em Psicologia do Trabalho e da Organização pela Universita degli Studi di Boligna - Itália

Instituição de vinculação: Universidade Estadual do Ceará

Fortaleza/CE - Brasil

Áreas de interesse em pesquisa: Aprendizagem, Ciência, Tecnologia e Inovação.

DIEGO DE QUEIROZ MACHADO diegoqueirozm@yahoo.com.br

Mestre em Administração de Empresas pela UECE

Instituição de vinculação: Universidade de Fortaleza

Fortaleza/CE - Brasil

Áreas de interesse em pesquisa: Gestão da Inovação, Aprendizagem Organizacional,

Desenvolvimento Sustentável e Filosofia do Conhecimento Científico.

\section{GERMANA FERREIRA ROLIM germanafrolim@gmail.com}

Mestre em Administração de Empresas pela UECE

Instituição de vinculação: Universidade Federal do Ceará

Quixadá/CE - Brasil

Áreas de interesse em pesquisa: Empreendedorismo e Estratégia.

\section{RAFAELLA ALVES MEDEIROS ALVARENGA rafaella.alves.medeiros@ gmail.com}

Mestre em Administração pela UNIFOR

Instituição de vinculação: Universidade de Fortaleza

Fortaleza/CE - Brasil

Áreas de interesse em pesquisa: Administração, APL, Sustentabilidade. 